\title{
The relationship between Motivation, Perceived Motivational Climate, Task and Ego Orientation, and Perceived Coach Autonomy in young ice hockey players
}

\author{
Arne Martin Jakobsen \\ Nord University - Sport, Bodø, Norway
}

\section{abstract}

Background: This study is grounded in the theory of self-determination, the achievement goal theory, and the theory of perceived motivational climate. The goal of the study was to examine the relationships among perceived coach autonomy, motivation, task and ego orientation, and the perceived motivational climate in young ice hockey players.

Material and methods: The participants included 401 ice hockey players aged 14-18 years old. To calculate the power of prediction between the independent variable "perceived autonomy from the coach", all 6 factors of motivation in the self-determination theory (SDT) and the goal orientation we conducted two path diagrams: one where task environment was the dependent variable and one with ego environment as the dependent variable. Between these factors and goal orientation among the players and the dependent variables, a hierarchical regression analysis was employed.

Results: We found that high perceived autonomy support from the coach positively influences motivation in junior hockey players. Players who perceive autonomy support from their coach have a higher chance of scoring highly for autonomic regulation, according to self-determination theory.

Conclusions: This probably leads to more task-oriented players who create a more task-oriented environment, hopefully resulting in fewer players dropping out of the sport.

Key words: self-determination, motivation, Motivational Climate, Task and Ego Orientation, Perceived Coach Autonomy.

\section{article details}

Article statistics: Word count: 3,890; Tables: 2; Figures: 2; References: 86

Full-text PDF: Received: November 2020; Accepted: March 2021; Published: June 2021

Copyright http://www.balticsportscience.com

Indexation:

(c) Gdansk University of Physical Education and Sport, Poland

Celdes, Clarivate Analytics Emerging Sources Citation Index (ESCI), CNKI Scholar (China National Knowledge Infrastructure), CNPIEC, DOAJ, EBSCO - Central \& Eastern European Academic Source, EBSCO - SPORTDiscus, EBSCO Discovery Service, Google Scholar, Index Copernicus, J-Gate, Naviga (Softweco, Primo Central (ExLibris), ProQuest - Family Health, ProQuest - Health \& Medical Complete, ProQuest - Illustrata: Health Sciences, ProQuest Nursing \& Allied Health Source, Summon (Serials Solutions/ProQuest, TDOne (TDNet), Ulrich's Periodicals Directory/ ulrichsweb, WorldCat (OCLC)

Funding: This research received no specific grant from any funding agency in the public, commercial, or not-for-profit sectors. Author has declared that no competing interest exists. Arne Martin Jakobsen Nord University - Sport; Mørkvedhallen Mørkvedhallen Bodø 8049; Norway; T: 99739805; e-mail: arne.m.jakobsen@nord.no

Open Access License:

This is an open access article distributed under the terms of the Creative Commons Attribution-Non-Commercial-NoDerivatives 4.0 International (https://creativecommons.org/licenses/by-nc-nd/4.0/), which permits use, distribution and reproduction in any medium, provided the original work is properly cited, the use is non-commercial and is otherwise in compliance with the license. 


\section{INTRODUCTION}

Grounded in the framework of self-determination theory (SDT), over the last 30 years, numerous studies have investigated individuals' motivations in different settings [1-4]. People may engage in activities for different reasons [5-6]. When athletes engage in an activity for the satisfaction and pleasure derived from the activity, they are intrinsically motivated, whereas behaviors performed to attain material or social rewards are defined as providing extrinsic motivation [7-8]. Intrinsically motivated behaviors are associated with satisfaction of three psychological needs [2, 9]. There are needs for autonomy, competence, and relatedness. The basic needs hypothesis advanced by self-determination theory has also been examined in the context of sport [10-12].

For most participants, participation in sports is intrinsically motivated. People participate in sports due to intrinsic motives, such as enjoyment and interest, more often than due to extrinsic goals [13-14], whereas exercisers are more likely to be motivated by extrinsic motives, such as improving one's appearance. Contexts fostering autonomy and perceived competence enhance enjoyment and sustain motivation [15-19]. Sustained exercise is more likely to occur when a person has both well-internalized extrinsic motivation and intrinsic motivation [8, 20-23].

The motivation for engaging in sports and exercise extends beyond intrinsic motivation. People also have many extrinsic reasons for engaging in sports, from health reasons to a desire for recognition. Self-determination theory includes two broad classes of nonintrinsic motivation: extrinsic motivation, which is behavior motivated by expected outcomes that are not inherent to the activity itself, and amotivation, which is the lack of energy directed toward an action or intention [3, 21]. Extrinsic motivation can vary in the degree of self-determination along a self-determination continuum ranging from nonself-determined (extrinsic and introjected regulation) to self-determined (identified and integrated regulation) forms of extrinsic motivation. People are typically viewed as having multiple motives, both extrinsic and intrinsic ones [24-26].

Optimal motivational function is achieved through the satisfaction of a person's needs for autonomy, competence, and relatedness. Cognitive evaluation theory describes the environmental contingencies that lead to the adoption of intrinsically or extrinsically motivated behaviors. The organismic integration theory identifies the quality of motivation on a scale of perceived locus of causality. These causalities are ranked from highly autonomous to highly controlling [8, 27-29].

In his hierarchical model of intrinsic and extrinsic motivation, Vallerands [30-31] claims that different motivations exist at three levels of generality: the global, contextual, and situational levels. These social factors are mediated by perceived; self-determination, competence and relatedness, which leads to different types of motivation (intrinsic, extrinsic and amotivation). The consequences of this are global, contextual or situational; affect, cognition and behavior. Sport participation will be a part of the contextual level.

Intrinsically motivated behavior includes activities people do only for enjoyment, pleasure, and fun, where there are no rewards or discernible reinforcements involved [32-33]. Autonomous regulation is associated with actions and maintenance of change for exercise [27, 34], exercise-related self-esteem [35-36], greater physical fitness [37-38], more frequent self-reported exercise behaviors [39], and more positive attitudes toward exercise [37-38, 40]. Autonomy-supportive coaches acknowledge athletes' feelings and perspectives and allow them to be involved in the decision making process, while those adopting a controlling style are characterized by a highly directive style of interaction [41]. Perceived autonomy support from friends is positively associated with identified regulation and 
intrinsic motivation [39]. Perceived autonomy support from exercise instructors positively predicts relatedness, autonomy, competence need satisfaction, and intrinsic motivation $[27,42]$. Research has demonstrated the value of perceived autonomy support from the coach and task-involving climate in predicting the intrinsic motivation in athletes [43]. This study also suggested that perceived autonomy support from the coach can facilitate a later task-involving peer motivational climate.

Satisfaction of psychological needs is positively correlated with identified and introjected regulation and intrinsic motivation [37, 39, 44]. In terms of competence satisfaction, introjected and identified regulations can positively predict strenuous exercise behavior, whereas external regulation is a more negative predictor of strenuous exercise behavior [45]. Competence satisfaction also has both direct and indirect effects on behavioral investment.

People are driven to achieve for different reasons. According to the achievement goal theory, the reasons why they strive to achieve pertain to the standards for judging their own competence [46-48]. They orient themselves toward meeting these competence standards. If people endorse mastery goals, they are concerned with learning, growth, or understanding. In a sense, they are immersed in the achievement task itself and preoccupied with their own expertise in the domain. If they endorse performance goals, they are concerned about achievement in relation to others or with how competent they appear to others [49]. Task orientation focuses on self-referenced mastery or improvement in relation to one's own standards. Success is perceived when learning, improvement, and mastery are achieved [50]. Ego-oriented athletes are concerned with gaining positive judgements from others and compare their performance to that of competitors [51]. Achievement goal theory assumes that goal orientations are not bi-polar opposites of the same construct but, rather, are independent of each other. This means that an individual can be high and/or low in both orientations at any given time [51]

In psychology, the theory talks about ego- and task-oriented athletes. Ego-oriented athletes who rate their ability as inferior to that of competitors are vulnerable to somatic and cognitive anxiety before and during performance [52]. People are more likely to drop out of competitions, set standards for their performance that are unrealistically high or low, and rate competitions or evaluations as unimportant if they have a low estimate of ability and are ego-oriented [52]. Ego-oriented athletes often have pressure from coaches and parents to reach exact goals and have concerns about making mistakes. Task-oriented athletes may also set exact goals, but these goals conform to the athlete's own standard [53]. Ego-oriented athletes are also more likely to view their ability as fixed [54].

Athletes who are task-oriented are less vulnerable to somatic and cognitive anxiety [55]. They have more control over factors that lead to failure and success; this also contributes to heightened enjoyment [56] and intrinsic interest in sport [57-58].

Many athletes have multiple goal orientations. Optimal performance may result from the endorsement of moderate to high levels of ego and task orientations [59-60]. Top 10 athletes in major track and field championships are often driven by both ego and task goals [61]. A high task orientation may buffer the negative effects of a high ego orientation [60,62].

Elite British adolescent athletes with moderate ego/higher task goal orientation use more self-talk than athletes with higher ego/lower task and moderate task/lower ego goal orientations [63].

Coaches create motivational climates that encourage the development of task and ego orientations [64-66]. Task-oriented athletes are more likely to play for coaches who 
emphasize the mastery of enjoyment and skills. Effort results in success and improvement in task-involving climates. Ego-involving climates cause unequal recognition of participants, intra-team rivalry, and punishment for mistakes. Normative ability and deception are the most important factors in success [67]. A study among young Japanese ice hockey players demonstrated that a task involving a climate created by coaches may not only influence players' task goal orientations but also their ego orientations. An ego-involving climate created by coaches may also influence players' ego goal orientations [68].

Task-oriented environments are likely to provide athletes with positive emotional experiences. Ego-oriented climates evoke unpleasant emotional states [69]. Ego-involving climates are also associated with negative personal development [70], which leads to strategies that are unproductive for enhancing skills, for instance, avoidance of practice and claiming handicaps, such as fatigue and a lack of preparation [71]. In these climates, young athletes worry about success and failure and are less content with team membership [72-73]. Young athletes are more likely to drop out of sports when the motivational climate is highly ego-oriented and not mastery-oriented, and they judge their athletic ability as low [74-75]. A study on Finnish junior ice hockey players found that a motivational climate emphasizing effort, personal development and improvement, and the achievement of goal mastering tasks are significant for enjoyment in junior ice hockey [76].

Ego-involving climates elicit amotivation and performance anxiety and decrease intrinsic interest. Ego climates also leads to more drop out of sports [77].

In this study, we examined the general relationship between perceived coach autonomy, motivation, task and ego orientation, and perceived motivational climate in young ice hockey players. More specifically, the first aim of this study was to investigate the relationships among perceived autonomy from the coach, motivation, dispositional goal orientation, and the perceived motivational climate in 14-17-year-old Norwegian ice hockey players. The second aim was to investigate how perceived autonomy from the coach influences intrinsic motivation; integrated, identified, introjected, and external regulation; and amotivation.

We expected to find a positive path from the perceived autonomy support via the most autonomous motives to task involvement and then to the task environment. We also expected to find a negative path from perceived autonomy support from the coach via the most controlling motives to ego involvement and then to the ego environment. We expected to find a direct positive relationship between perceived autonomy from the coach and the task environment and a direct negative relationship between perceived autonomy from the coach and the ego environment.

In this study we will look into the relationship between perceived coach autonomy, motivation, task and ego orientation, and perceived motivational climate in young ice hockey players.

\section{MATERIAL AND METHODS}

\section{PARTICIPANTS}

Participants included 401 young Norwegian ice hockey players aged 14-18 years old. This is probably about $1 / 3$ of the players in this age. They were all voluntary participants on the Norwegian Ice Hockey federations talent camp. There was no selection of the players to the camp. Therefore, they should be representative of the whole population. Of the players, 49\% were 15 and 16 years old. There were 49 girls and 352 boys. Ninety-four of the players were in Norwegian national U-20 and U-18 teams. All players who were later 
selected to be part of the U-16 team also participated. Only 59 players also competed in another sport outside of ice hockey. There were 59 goal keepers, 127 defenders, 201 forwards, and 19 players who were both forwards and defenders. We obtained parental consent to their participation in the study.

\section{MeASURES}

The data were collected during a one-week hockey camp arranged by the Norwegian hockey federation. The players had one hour to complete the questionnaires.

We used the Sport Motivation Scale (SMS-II) questionnaire [78] to measure the players' motivation. This is a revised version of the SMS [79], containing 18 questions on 6 factors: intrinsic regulation, integrated regulation, identified regulation, introjected regulation, external regulation, and amotivation. All factors yielded reliable values with Cronbach's $\alpha$ scores between 0.57 and 0.72 . Given the small number of items forming the factors, the internal validity observed can be marginally accepted [80]. Each factor contains three questions. The players were asked why they played ice hockey and had to answer on a 7-point Likert-type scale from 1 to 7 ( $1=$ do not agree at all, to $7=$ completely agree $)$.

To examine the perceived coach autonomy support, we used a short version of the Sport Climate Questionnaire (SCQ) [81] with 6 items $(\alpha=0.82)$ worded in terms of "my coach". They were answered on a Likert-type scale from 1 to 7 ( $1=$ do not agree at all, to $7=$ completely agree). A high average score represented a high level of perceived autonomy support.

To measure the dispositional goal orientation, we used the Task and Ego orientation in Sport Questionnaire (TEOSQ) [82-83]. The TEOSQ has a two-factor structure representing task (7 items, $\alpha=0.82$ ) and ego (6 items, $\alpha=0.87$ ) orientations. As the questionnaire was administered in an ice hockey context, players were encouraged to think about how successful they felt in relation to their team, and then they indicated on a 5-point Likerttype scale $(1=$ strongly disagree to $5=$ strongly agree) whether they agreed or disagreed with items reflecting a task orientation (e.g., "I feel successful when I work really hard") or ego orientation (e.g., "I feel successful when others cannot do as well as me").

The Perceived Motivational Climate in Sport Questionnaire-2 (PMCSQ-2) was created to determine the athletes' perceptions of goals operating in an athletic setting [67, 84]. The PMCSQ-2 has six subscales, which are transformed into two higher-order scales labeled task-involving (17 items, $\alpha=0.88$ ) (including cooperative learning $\alpha=0.74$, important role $\alpha=0.80$, and effort/improving $\alpha=0.79$ scales) and ego-involving (16 items, $\alpha=0.91$ ) (including punishment for mistakes $\alpha=0.80$, unequal recognition $\alpha=0.89$, and intrateam rivalry $\alpha=0.52$ ). Confirmatory factor analysis revealed that the six-factor model is marginally acceptable (with an intrateam rivalry subscale of $\alpha=0.54[67,85]$. To complete the PMCSQ-2, the players were requested to think about their participation in ice hockey and to indicate, on a 5 -point Likert type scale ( $1=$ strongly disagree to $5=$ strongly agree), whether they agreed with claims reflecting a task- (e.g., "in my team, players are encouraged to work on weaknesses") or ego-involving climate (e.g., "in my team, players are encouraged to outdo their teammates").

\section{STATISTICAL ANALYSIS}

IBM SPSS Statistics 26 was used for calculation. Descriptive statistics, means, and standard deviations were obtained for all variables. Simple correlations were calculated to test relationships among all variables. To calculate the power of prediction between the independent variable "perceived autonomy from the coach", all 6 factors of motivation in the self-determination theory (SDT) and the goal orientation we conducted two path diagrams: one where task environment was the dependent variable and one with ego 
environment as the dependent variable (Figures 1 and 2). Between these factors and goal orientation among the players and the dependent variables, a hierarchical regression analysis was employed. In this analysis, task and ego environments constituted the dependent variables. Only the paths showing significant relationships were included in the models. We tested for correlations between residuals with the Durbin-Watson statistic. Collinearity diagnostics were conducted by using the variance inflation factor (VIF) [80].

\section{RESULTS}

Descriptive statistics, including means, standard deviations, and Cronbach $\alpha$ levels, as well as correlation statistics, are reported in Table 1. The descriptive statistics for the entire sample revealed high levels of intrinsic motivation (mean $(M)=5.99$ ), integrated regulation $(M=6.0)$, and identified regulation $(M=5.73)$. We found moderately high levels of introjected $(\mathrm{M}=5.34)$ and external $(\mathrm{M}=4.43)$ regulation and a low level of amotivation $(\mathrm{M}=1.55)$. Task involvement was associated with a high level of intrinsic motivation $(\mathrm{M}=4.52)$ and ego involvement $(\mathrm{M}=3.01)$, while autonomy support from the coach $(M=4.73)$ showed moderate levels.

When examining the correlation coefficients for the five motivation subscales (Table 1 ), the observed relationships showed that the theoretically closer factors were more strongly correlated. When examining the links between the motivational variables and the perceived autonomy, goal orientation, and perceived motivational climate, we observed that the most self-determined motivational variables had the strongest correlations with task involvement, autonomy support, and task environment. Task involvement had positive correlations with autonomy support and task environment, whereas ego involvementwas only correlated with an ego environment.

Table 1. Descriptive statistics and internal consistency for each measure and bivariate correlations among study variables

\begin{tabular}{|c|c|c|c|c|c|c|c|c|c|c|c|}
\hline & 1 & 2 & 3 & 4 & 5 & 6 & 7 & 8 & 9 & 10 & 11 \\
\hline \multicolumn{12}{|l|}{ 1.Intrinsic motivation } \\
\hline 2.Integrated regulation & $0.61 * *$ & & & & & & & & & & \\
\hline 3.Identified regulation & $0.56 * *$ & $0.66^{* *}$ & & & & & & & & & \\
\hline 4.Introjected regulation & $0.40 * *$ & $0.55^{* *}$ & $0.54 * *$ & & & & & & & & \\
\hline 5.External regulation & $0.20 * *$ & $0.24 * *$ & $0.28 * *$ & $0.53^{* *}$ & & & & & & & \\
\hline 6. Amotivation & $-0.28 * *$ & $-0.32 * *$ & $-0.16 * *$ & $-0.18^{* *}$ & 0.06 & & & & & & \\
\hline 7.Task involvement & $0.51 * *$ & $0.48^{* *}$ & $0.45^{* *}$ & $0.40 * *$ & $0.14 * *$ & $-0.35^{* *}$ & & & & & \\
\hline 8.Ego involvement & 0.00 & $0.13^{*}$ & $0.13^{*}$ & $0.23 * *$ & $0.28 * *$ & $0.07 * *$ & 0.07 & & & & \\
\hline $\begin{array}{l}\text { 9.Autonomy support } \\
\text { from the coach }\end{array}$ & $0.26 * *$ & $0.23^{* *}$ & $0.22 * *$ & 0.06 & 0.09 & $-0.13 *$ & $0.21 * *$ & 0.04 & & & \\
\hline 10.Task environment & $0.41 * *$ & $0.35^{* *}$ & $0.35^{* *}$ & $0.19 * *$ & $0.12 *$ & $-.19 * *$ & $0.41 * *$ & 0.06 & $0.53^{* *}$ & & \\
\hline 11.Ego environment & $-0.11 *$ & 0.05 & 0.10 & $0.17 * *$ & $0.25^{* *}$ & $0.22 * *$ & -0.05 & $0.31^{* *}$ & $-0.39 * *$ & $-0.37 * *$ & \\
\hline $\mathrm{N}$ & 396 & 391 & 395 & 393 & 396 & 394 & 398 & 393 & 390 & 375 & 379 \\
\hline M & 5.99 & 6.00 & 5.73 & 5.34 & 4.43 & 1.55 & 4.52 & 3.01 & 4.73 & 4.19 & 2.73 \\
\hline SD & 0.97 & 0.91 & 1.06 & 1.19 & 1.38 & 0.82 & 0.50 & 0.92 & 1.34 & 0.54 & 0.81 \\
\hline$\alpha$ & 0.65 & 0.66 & 0.72 & 0.57 & 0.64 & 0.64 & 0.82 & 0.87 & 0.82 & 0.91 & 0.88 \\
\hline
\end{tabular}


We divided ego and task involvement into three different groups, where 1 and 2 were low, 3 was moderate, and 4 and 5 were high, and then created new variables. Table 2 shows that 34 participants (8.7\%) were moderately task- and ego-involved, 227 (58.1\%) were high task-involved and moderately ego-involved, 60 (15.3\%) were high task-involved and high ego-involved, and 61 (15.6\%) were high task-involved and low ego-involved.

Table 2. Cross tabulation of task and ego involvement among the players, divided into low, moderate and high

\begin{tabular}{|c|c|c|c|c|c|c|}
\hline & & & \multicolumn{3}{|c|}{ Ego orientation } & \multirow{2}{*}{ Total } \\
\hline & & & Low & Moderate & High & \\
\hline \multirow{6}{*}{ 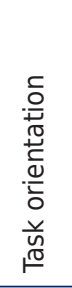 } & \multirow{2}{*}{ Low } & Count & 1 & 0 & 0 & 1 \\
\hline & & $\%$ of Total & $0.3 \%$ & $0.0 \%$ & $0.0 \%$ & $0.3 \%$ \\
\hline & \multirow{2}{*}{ Moderate } & Count & 6 & 34 & 2 & 42 \\
\hline & & $\%$ of Total & $1.5 \%$ & $8.7 \%$ & $0.5 \%$ & $10.7 \%$ \\
\hline & \multirow{2}{*}{ High } & Count & 61 & 227 & 60 & 348 \\
\hline & & $\%$ of Total & $15.6 \%$ & $58.1 \%$ & $15.3 \%$ & $89.0 \%$ \\
\hline \multirow{2}{*}{ Total } & & Count & 68 & 261 & 62 & 391 \\
\hline & & $\%$ of Total & $17,4 \%$ & $66.8 \%$ & $15.9 \%$ & $100.0 \%$ \\
\hline
\end{tabular}

In the first path model (Figure 1), task environment was used as the dependent variable. Autonomic support from the coach was found to have a significant direct positive relationship with the dependent variable $(\mathrm{p}<0.01)$ but also a positive significant relationship via intrinsic motivation and identified regulation $(\mathrm{p}<0.01)$ (Figure 1$)$. We also found a negative relationship via amotivation $(\mathrm{p}<0.05)$. Intrinsic motivation was found to have a significant direct positive relationship with the dependent variable "task environment" $(p<0.01)$. Task involvement was found to have a positive relationship with three of the motivational factors: intrinsic motivation $(\mathrm{p}<0.01)$, identified $(\mathrm{p}<0.05)$, and introjected $(\mathrm{p}<0.01)$ regulation. Amotivation was found to have a negative relationship with task involvement $(\mathrm{p}<0.01)$. Ego involvement was identified to have a negative relationship with intrinsic motivation $(p<0.05)$ and a positive relationship with external regulation $(p<0.05)$. Lastly, we found a positive relationship for task involvement and a negative relationship for ego involvement (both $\mathrm{p}<0.01$ ) with the dependent variable "task environment". The whole model explained $40 \%$ of the variance.

Model 2 (Figure 2) consisted of the same independent and intermediate variables as model 1. The paths between the variables were identical to those in model 1 . The difference here was the dependent variable, "ego environment". The whole model explained $34 \%$ of the variance. The independent variable "autonomy support from the coach" was found to have a direct negative relationship with the dependent variable at the $1 \%$ level. It also had an indirect negative relationship via intrinsic motivation and amotivation. We found an indirect positive relationship via integrated regulation. We already observed that ego involvement had a negative relationship with intrinsic motivation and a positive relationship with external regulation and therefore has a relationship with the dependent variable "ego environment" through the intermediate variable ego involvement. The intermediate variables external regulation and amotivation were shown to have direct positive relationships with the dependent variable (both $\mathrm{p}<0.01$ ). Intrinsic motivation was shown to have a direct negative relationship with ego environment. Lastly, we found a positive relationship between the intermediate variable ego involvement and the dependent variable at the $1 \%$ level. No significant relationship was found between task involvement and ego environment. 


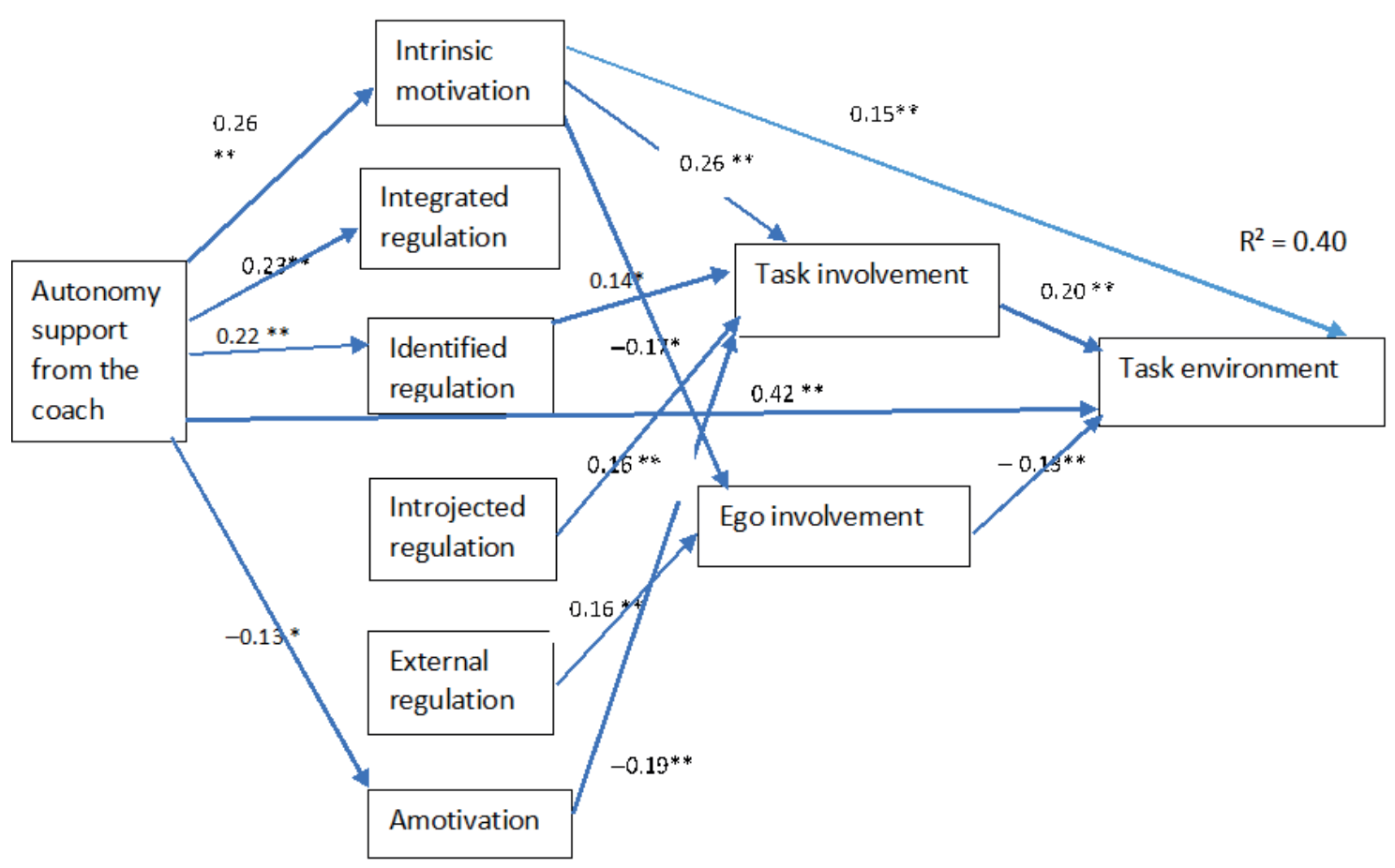

$* * p<0.01 * p<0.05$

Fig. 1. Path model of the relationships among perceived coach autonomy, through motivation, task and ego orientation, and the dependent variable task environment - Model 1

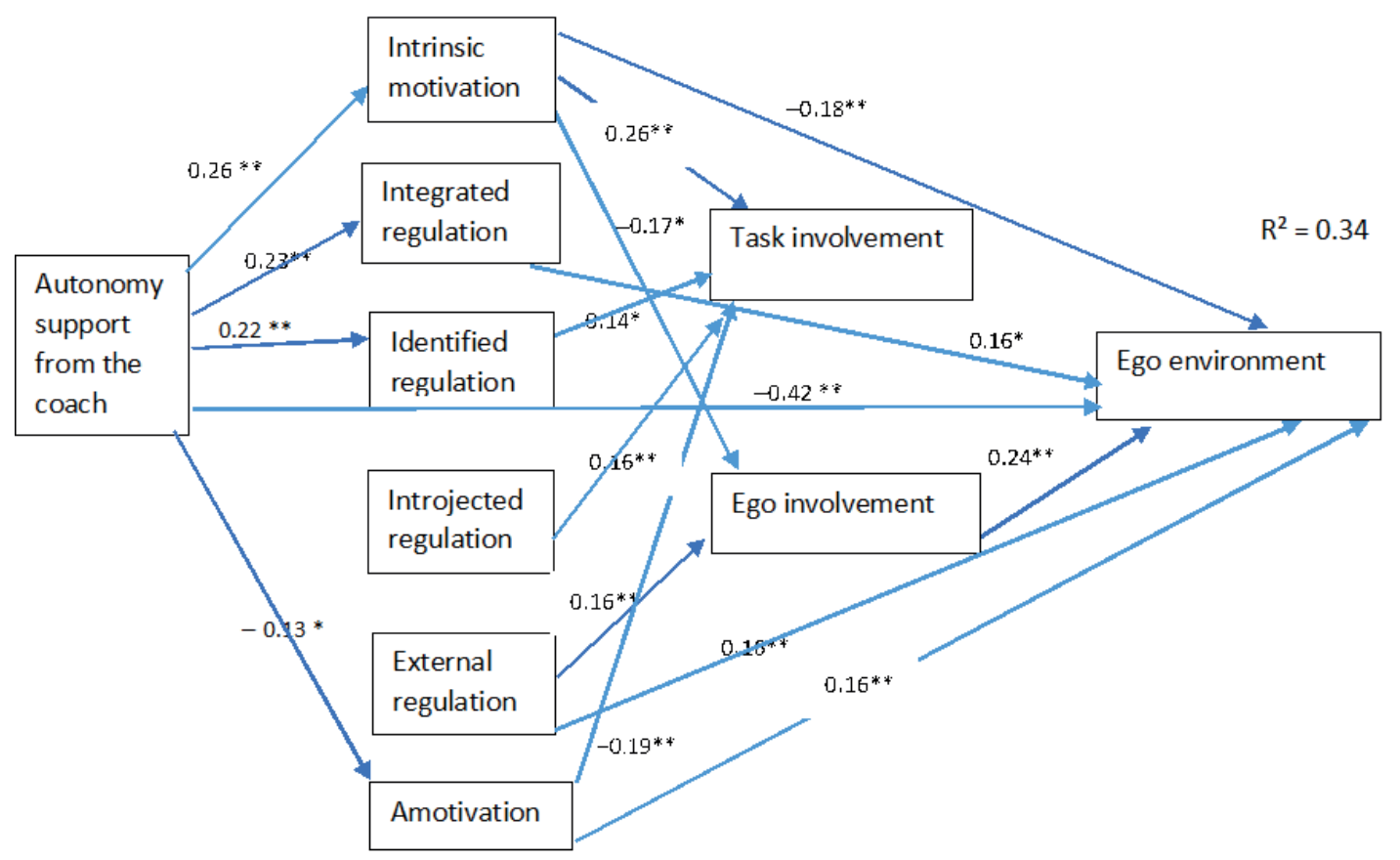

$* * p<0.01 * p<0.05$

Fig. 2. Path model of the relationships among perceived coach autonomy, through motivation, task and ego orientation, and the dependent variable ego environment - Model 2 


\section{DISCUSSION}

The purpose of this study was to look into the relationship between perceived coach autonomy, motivation, task and ego orientation, and the perceived motivational climate in young Norwegian ice hockey players.

As we expected, the sample of national team hockey players scored highly for intrinsic motivation, and most of them showed autonomous regulation of extrinsic motivation. They also scored highly for introjected regulation, which means that they try to avoid external sources of disapproval or try to gain externally referenced approval [8]. They also scored highly for task involvement and had medium scores for ego involvement. Most players (58\%) were found to be high task-moderate ego involved. The theory confirms that optimal performance may result from endorsement of moderate to high levels of ego and task orientations [59-60]. Positively, most Norwegian ice hockey players perceive the motivational climate as being task-oriented as we know that task-oriented environments are more likely to give athletes positive emotional experiences and ego-oriented climates evoke unpleasant emotional states [69]

The first aim of this study was to investigate the relationships among perceived autonomy from the coach, motivation, dispositional goal orientation, and the perceived motivational climate in 14-17-year-old Norwegian ice hockey players. We found that theoretically related factors were more strongly correlated. Intrinsic motivation was found to correlate strongly with integrated and identified regulation, task involvement, and the task environment. At the same time, it did not correlate with ego involvement and had a negative correlation with amotivation $(p<0.01)$ and ego environment $(p<0.05)$. We also observed significant negative correlations among amotivation, task involvement, autonomy from the coach, and task environment. These results are as expected [52, 65-66, 75].

The second aim was to investigate how perceived autonomy from the coach influences the task environment via intrinsic motivation; integrated, identified, introjected, and external regulation; amotivation; and task- and ego-involvement. As expected, we found a significant $(\mathrm{p}<0.01)$ positive link between perceived autonomy support from the coach, intrinsic motivation, and integrated- and identified regulation [86]. We also observed a negative correlation between autonomy support from the coach and amotivation. There was, as expected, a direct positive $(\mathrm{p}<0.01)$ link between autonomy support from the coach and task environment [27,42-43]. This indicates that coaches who give their players autonomy support have a better chance of creating a task environment, which encourages effort from the players. A task-oriented motivational climate emphasizing effort, personal development, improvement, and achievement goal mastering tasks. This is important for enjoyment in junior ice hockey [76]. We also observed a path from intrinsic motivation to task involvement and from task-involved athletes to the development of a task environment. There was also a direct association between intrinsic motivation and task environment. Identified and introjected regulation were found to indirectly influence the development of a task environment via task involvement. No association was found between integrated regulation and task involvement, which was unexpected. It is not easy to explain why, as integrated regulation is the most autonomous extrinsic motive. This should be investigated further. There was a negative path from intrinsic motivation via ego involvement to task environment. To summarize, the results from our study indicate that perceived autonomy support from the coach will lead to higher intrinsic motivation and identified regulation, which will lead to more task-involved athletes, which then influence the environment to be a more task-motivated climate [64]. Hopefully, this will lead to ice hockey players who rate their abilities as being higher than those of their competitors and who are less vulnerable to somatic and cognitive anxiety before and during performance. They will also be less likely to drop out of competitions, will set standards for their performance that are realistically high, and will rate evaluations as important [52, 64-66]. 
The last aim of the study was to investigate how perceived autonomy from the coach influences intrinsic motivation; integrated, identified, introjected, and external regulation; and amotivation via ego- and task-involvement; and finally, whether it represents a path to ego environment. We found that a lack of perceived autonomy support from the coach had a direct significant $(p<0.01)$ effect on the development of an ego environment. If the athletes perceived low autonomy support from their coach, the development of an ego environment was more likely. Athletes who scored highly on external regulation were more ego-involved, and the possibility was higher that the environment would be more ego-oriented. The less autonomic the regulation, the greater the possibility that athletes are ego-involved, and the more an ego-oriented environment will develop. There is one exception: the players with a high score on integrated regulation, which is a highly autonomous motive, had a positive relationship with ego environment. This could because, if the players have a highly integrated regulation, an ego environment does not infect them too much. This finding is also partly supported by earlier research [64-65, 72, 75].

Limitations of the study. The inclusion and selection of the players can be a limitation when we talk about representativeness. The players in this study include the best players in this age group. They were all participants at the Norwegian ice hockey federations talent camp. The rationale for this decision was that it simplified the collection of data. It would also be interesting to do the same research in another sport to compare the results. Another limitation of this study is the players' age and the use of questionnaires that are validated for older participants.

\section{CONCLUSIONS}

We found that high perceived autonomy support from the coach positively influences motivation in junior hockey players. Players who perceive autonomy support from their coach have a higher chance of scoring highly for autonomic regulation, according to self-determination theory $[64,81]$ This probably leads to more task-oriented players who create a more task-oriented environment, hopefully resulting in fewer players dropping out of the sport.

\section{REFERENCES}

[1] Deci EL, Ryan RM. Intrinsic motivation and self-determination in human nature. Plenum Press: New York; 1985. https://doi.org/10.1007/978-1-4899-2271-7

[2] Deci EL, Ryan RM. The "what" and "why" of goal pursuits: Human needs and Self-determination of Behavior. Psycholog Inq. 2000;11(4):227-268. https://doi.org/10.1207/S15327965PLI1104_01

[3] Ryan RM, Deci EL. Self-determination theory and the facilitation of intrinsic motivation, social development, and well-being. Am Psychologist. 2000;55(1):68-78. https://doi.org/10.1037/0003-066X.55.1.68

[4] Ryan RM, Deci EL. Self-Determination Theory, Basic Psychological Needs in Motivation, Development, and Wellness. The Guilford Press: New York; 2017. https://doi.org/10.1521/978.14625/28806

[5] Vallerand R, Intrinsic and extrinsic motivation in sport and physical activity: A review and a look in the future. In: Tennenbaum G, Eklund RE, eds. Handbook of Sport Psychology, 3 ed. John Wiley: New York; $2007,255-279$.

[6] Vallerand R. A Hierarchical model of intrinsic and extrinsic motivation for sport an physical activity. In: Hagger MS, Chatzisarantis NLD, Eds. Intrinsic motivation and self-determination in exercise and sport. Champaign IL: Human Kinetics; 2007, 255-279. https://doi.org/10.5040/9781718206632.ch-017

[7] Gillet N, Rosnet, E., Basic Need Satisfaction and Motivation In Sport. Athletic Insight 2008, 1(10(3)):1-13.

[8] Ryan RM, Deci EL. Active human nature. In: Intrinsic motivation and self-determination in exercise and sport. Champaign IL: Human Kinetics; 2007. https://doi.org/10.5040/9781718206632.ch-017

[9] Deci EL, Ryan RM. A motivational approach to self: Integration in personality. In: Dienstbier R, editor. Nebraska symposium on motivation. Vol. 38. Lincoln NE: University of Nebraska Press; 1991, 237-288.

[10] Gagné M, Ryan RM, Bargmann K. Autonomy support and need satisfaction in the motivation and well-being of gymnasts. J Appl Sport Psychol. 2003;15:372-389. https://doi.org/10.1080/714044203

[11] Sylvester BD, Curran T, Standage M, Sabiston, CM. Predicting exercise motivation and exercise behavior: A moderated mediation model testing the interaction between perceived exercise variety and basic psychological needs satisfaction. Psychol Sport Exerc. 2018;36:50-56. https://doi.org/10.1016/j.psychsport.2018.01.004

[12] Chu TL, Zhang J. The roles of coaches, peers, and parents in athletes' basic psychological needs: A mixed-studies review. Int J Sport Sci Coach. 2019;14(4):569-588. https://doi.org/10.1177/1747954119858458 
[13] Vallerand RJ, Losier GF. An integrative analysis of intrinsic and extrinsic motivation in sport. J Appl Sport Psychol. 1999;11(1):142-169. https://doi.org/10.1080/10413209908402956

[14] Verloigne M, De Bourdeaudhuij I, Tanghe A, et al. Self-determined motivation towards physical activity in adolescents treated for obesity: An observational study. Int J Behav Nutr Phys Act. 2011; 8. https://doi.org/10.1186/1479-5868-8-97

[15] Chatzisarantis NLD, Hagger MS, Biddle SJH, Karageorghis C. The cognitive processes by which perceived locus of causality predicts participation in physical activity. J Health Psychol. 2002;7(6):685-699. https://doi. org/10.1177/1359105302007006872

[16] Hagger MS, Chatzisarantis NLD, Culverhouse T, Biddle SJH. The processes by which perceived autonomy support in physical education promote leisure-time physical activity intentions and behavior: A trans-contextual model. J Educ Psychol. 2003;(95):784-795. https://doi.org/10.1037/0022-0663.95.4.784

[17] Hagger MS, Armitage CJ. The influence of perceived loci of control and causality in the theory of planned behavior in a leisure-time exercise context. J Appl Behav Res. 2004;9(1):45-64. https://doi.org/10.1111/j.1751-9861.2004.tb00091.x

[18] Hagger MS, Chatzisarantis NLD, Harris J. The process by which relative autonomous motivation affects intentional behavior: Comparing effects across dieting and exercise behaviors. Motivation and Emotion 2006;30(4):307-321. https://doi.org/10.1007/s11031-006-9046-5

[19] Hancox J, Quested E, Ntoumanis N, Thogersen-Ntoumanis C. Putting self-determination theory into practice: application of adaptive motivational principles in the exercise domain. Qualit Res Sport Exerc Health. 2018;10(1):75-91. https:// doi.org/10.1080/2159676X.2017.1354059

[20] Duncan LR, Hall GR, Wilson PM, Jenny O. Exercise motivation: a cross-sectional analysis examining its relationships with frequency, intensity, and duration of exercise. Int J Behav Nutr Phys Act. 2010;7:1-7. https://doi.org/10.1186/14795868-7-7

[21] Ryan RM, Deci EL. An overview of Self-Determination Theory: An organismic-dialectical perspective. In: Deci E L, Ryan RM, Eds. Handbook of Self-Determination Research. New York: University of Rochester Press; 2002.

[22] Smith AL, Ntoumanis N, Duda JL, Vansteenkiste M. Goal striving, coping, and well-being: A prospective investigation of the self-concordance model in sport. J Sport Exerc Psychol. 2011;33(1):124-145. https://doi.org/10.1123/jsep.33.1.124

[23] Vlachopoulos SP, Ntoumanis N, Smith AL. The basic psychological needs in exercise scale: Translation and evidence for cross-cultural validity. Int J Sport Exerc Psychol. 2010;8(4):394-412. https://doi.org/10.1080/1612197X.2010.9671960

[24] Hagger MS, Chatzisarantis NLD. Self-Determination Theory and the psychology of exercise. Int Rev Sport Exerc Psychol. 2008;1(1):79-103. https://doi.org/10.1080/17509840701827437

[25] Lonsdale C, Sabiston CM, Taylor IM, Ntoumanis N. Measuring student motivation for physical education: Examining the psychometric properties of the Perceived Locus of Causality Questionnaire and the Situational Motivation Scale. Psychol Sport Exerc. 2011;12(3):284-292. https://doi.org/10.1016/j.psychsport.2010.11.003

[26] Ryan RM, Connel JP. Perceived locus of causality and internalization: Examining reason for acting in two domains. Contemp Educ Psychol. 1989;25:54-67.

[27] Edmunds J, Ntoumanis N, Duda JL. Perceived Autonomy Support and Psychological Need Satisfaction in Exercise. In: Hagger MS, Chatzisarantis NLD, Eds. Intrinsic Motivation and Self-Determination in exercise and sport. Champaign, IL: Human Kinetics; 2007. https://doi.org/10.5040/9781718206632.ch-002

[28] Markland D, Ingledew DK. Exercise Participation Motives. In: Hagger MS, Chatzisarantis NLD, Eds. Intrinsic Motivation and Self-Determination in exercise and sport. Champaign, IL: Human Kinetics; 2007. https://doi. org/10.5040/9781718206632.ch-001

[29] McLachlan S, Hagger MS. Do people differentiate between intrinsic and extrinsic goals for physical activity? J Sport Exerc Psychol. 2011;33(2):273-288. https://doi.org/10.1123/jsep.33.2.273

[30] Vallerand RJ. Toward a hierarchical model of intrinsic and extrinsic motivation. In: Zanna MP, editor. Advances in experimental social psychology. Vol. 29. New York: Academic Press; 1997, 271-360. https://doi.org/10.1016/S00652601(08)60019-2

[31] Vallerand R, Ratelle CF. Intrinsic an extrinsic motivation: A hierarchical model. In: Deci EL, Ryaa RM, Eds., Handbook of Self-Determination Research. Rochester NY: the University of Rochester Press; 2002, 37-63.

[32] Bagoien TE, Halvari H. Autonomous motivation: Involvement in physical activity and perceived sport competence: Structural and mediator models. Percept Motor Skill. 2005;100:3-21. https://doi.org/10.2466/pms.100.1.3-21

[33] Hagger MS, Chatzisarantis NLD. Advances in self-determination theory research in sport and exercise. Psychol Sport Exerc. 2007;8(5):597-599. https://doi.org/10.1016/j.psychsport.2007.06.003

[34] Landry JB, Solomon M. African American women's self-determination across the stages of change for exercise. J Sport Exerc Psychol. 2004;(26):457-469. https://doi.org/10.1123/jsep.26.3.457

[35] Wilson PM, Rodgers WM, Fraser SN, Murray TC. The relationship between exercise regulations and motivational consequences in university students. Res Q Exerc Sport. 2004;75(1):81-91. https://doi.org/10.1080/02701367.200 4.10609136

[36] Wilson KB, Rodgers WM. The relationship between perceived autonomy support, exercise regulations and behavioral intentions in women. Psychol Sport Exerc. 2004;(5):229-242. https://doi.org/10.1016/S1469-0292(03)00003-7

[37] Stanley DM, Cumming J, Standage M, Duda JL. Images of exercising: Exploring the links between exercise imagery use, autonomous and controlled motivation to exercise, and exercise intention and behavior. Psychol Sport Exerc. 2012;13(2):133-141. https://doi.org/10.1016/j.psychsport.2011.10.002

[38] Wilson PM, Rodgers WM, Blanchard CM, Gessell J. The relationship between Psychological Needs, Self-Determined Motivation, Exercise Attitudes, and Physical Fitness. J Appl Soc Psychol. 2003;33(11):2373-2392. https://doi. org/10.1111/j.1559-1816.2003.tb01890.x

[39] Wilson KB, Rodgers WM, Fraser SN. Examining the psychometric properties of the behavioral regulation in exercise questionnaire. Measurement Phys Educ Exerc Sci. 2002;(6):1-21. https://doi.org/10.1207/S15327841MPEE0601_1

[40] Behzadnia B, Mohammadzadeh H, Ahmadi M. Autonomy-supportive behaviors promote autonomous motivation, knowledge structures, motor skills learning and performance in physical education. Curr Psychol. 2019;38(6): 1692-1705. https://doi.org/10.1007/s12144-017-9727-0 
[41] Mageau GA, Vallerand RJ. The coach-athlete relationship: A motivational model. J Sport Sci. 2003;21(11):883-904. https://doi.org/10.1080/0264041031000140374

[42] Chu T, Zhang X, Lee J, Zhang T. Perceived coach-created environment directly predicts high school athletes' physical activity during sport. Int J Sport Sci Coach. 2021;16(1):70-80. https://doi.org/10.1177/1747954120959733

[43] Jöesaar H, Hein V, Hagger MS. Youth athletes' perception of autonomy support from the coach, peer motivational climate and intrinsic motivation in sport setting: One-year effects. Psychol Sport Exerc. 2012;13:257-262. https:// doi.org/10.1016/j.psychsport.2011.12.001

[44] Stuart J. Enjoyment based motivation and enjoyable exercise experience in Generation Y sample: A mixed methods approach. Master, Georgia Southern University; 2013.

[45] Jakobsen AM. Are there differences in motives between participants in individual sports compared to team sports? Lase J Sport Sci. 2014;5(2):32-43. https://doi.org/10.1515/ljss-2016-0030

[46] Ames C, Archer J. Achievement goals in the classroom: Student's learning strategies and motivation processes. J Educ Psychol. 1988;80(3):260-267. https://doi.org/10.1037/0022-0663.80.3.260

[47] Dweck CS, Leggett EL. A social-cognitive approach to motivation and personality. Psychol Rev. 1988;95(2):256-273. https://doi.org/10.1037/0033-295X.95.2.256

[48] Pintrich PR. A motivational science perspective on the role of student motivation in learning and teaching contexts. J Educ Psychol. 2000;95(4):667-686. https://doi.org/10.1037/0022-0663.95.4.667

[49] Kaplan A, Gheen M, Midgley C. Classroom goal structure and student disruptive behavior. Br J Educ Psychol. 2002;72 (2):191-211. https://doi.org/10.1348/000709902158847

[50] Williams L. Goal orientations and athletes' preferences for competence information sources. J Sport Exerc Psychol. 1994;16:416-430. https://doi.org/10.1123/jsep.16.4.416

[51] Nicholls JG. The competitive ethos and democratic education. Cambridge, MA: Harvard University Press; 1989.

[52] Duda JL, Nicholls JG. Dimensions of achievement motivation in school, work and sport. J Educ Psychol. 1992;84: 290-299. https://doi.org/10.1037/0022-0663.84.3.290

[53] Dunn JGH, Causgrove Dunn J, Syrotuik DG. Relationship between specific and global measure of perfectionism in competitive female figure skaters. J Sport Exerc Psychol 2002;24:376-395. https://doi.org/10.1123/jsep.24.4.376

[54] Donovan JS, Williams KJ. Minding the mark. Effects of time and causal attributions on goal revision in response to goal performance descriptions. J Appl Psychol. 2003;88:379-390. https://doi.org/10.1037/0021-9010.88.3.379

[55] Hall HK, Kerr AW. Motivational antecedents of precompetitive anxiety in youth sport. Sport Psycholog. 1997;11:24-42. https://doi.org/10.1123/tsp.11.1.24

[56] McCarthy PJ, Jones MV, Clark-Carter D. Understanding enjoyment in youth sport: A developmental perspective. Psychol Sport Exerc. 2008;9:142-156. https://doi.org/10.1016/j.psychsport.2007.01.005

[57] Duda JL, Hall H. Achievement goal theory in sport. Recent extensions and future directions. In: Singer RN, Hausenblas HA, Janelle CM, Eds. Handbook of sport psychology, 2nd ed. New York, NY: Wiley; 2001, 417-433.

[58] Roberts GC, Treasure DC, Conroy DE. Understanding the dynamics of motivation in sport and physical activity. Anticipation and decision making. In: Tennenbaum G, Eklund RC, Eds. Handbook of sport psychology, 3rd ed. New York, NY: Wiley; 2007, 3-30.

[59] Barron KE, Harackiewicz JM. Achievement goals and optimal motivation: Testing multiple goal models. J Personal Soc Psychol. 2001;80:706-722. https://doi.org/10.1037/0022-3514.80.5.706

[60] Burton D, Gillham A, Glenn S. Motivational styles: Examining the impact of personality on the self-talk patterns of a adolescent female soccer player. Journal of Applied Sport Psychology 2011, 23, 413-428. https://doi.org/10.1080 /10413200.2011.568469

[61] Mallet CJ, Hanrahan SJ. Elite athletes: Why does the "fire" burn so brigthly? Psychol Sport Exerc. 2004;5:183-200. https://doi.org/10.1016/S1469-0292(02)00043-2

[62] Hodge K, Petlichkoff L. Goal profiles in sport motivation: A cluster analysis. J Sport Exerc Psychol. 2000;22:256-272. https://doi.org/10.1123/jsep.22.3.256

[63] Harwood C, Cumming J, Fletcher D. Motivational profiles and psychological skills use within elite youth sport. J Appl Soc Psychol. 2003;16:317-332. https://doi.org/10.1080/10413200490517986

[64] Boyce BA, Gano-Overway LA, Campbell AL. Perceived motivational climate's influence on goal orientations, perceived competence and practice strategies across the athletic season. J Appl Sport Psychol. 2009;21:381-394. https://doi. org/10.1080/10413200903204887

[65] Smith RE, Smoll FL, Cumming SP. Motivational climate and changes in young athletes' achievement goal orientations. Motivation and Emotion. 2009;33:173-183. https://doi.org/10.1007/s11031-009-9126-4

[66] Vazou S. Variations in perception of peer and coach motivational climate. Res Q Exerc Sport. 2010;81:199-211. https://doi.org/10.1080/02701367.2010.10599667

[67] Newton M, Duda JL, Yin Z. Examination of the psychometric properties of the Perceived Motivational Climate in Sport Questionaire-2 in a sample of female athletes. J Sport Sci. 2000;18:1-16. https://doi.org/10.1080/026404100365018

[68] Saotome H, Harada K, Nakamura Y. The relationship between change in perceived motivational climate and change in goal orientations among Japanese ice hockey players. Int J Sport Sci Coach. 2012;17(1):81-88. https://doi. org/10.1260/1747-9541.7.1.81

[69] Bortoli L, Bertollo M, Comani S, Robazza C. Competence achievement goals, motivational climate, and pleasant psychobiosocial states in youth sport. J Sport Sci. 2011;29:171-180. https://doi.org/10.1080/02640414.2010.530675

[70] MacDonald DJ, Cote J, Eys M, Deakin J. The role of enjoyment and motivational climate in relation to personal development of team sport athletes. Sport Psycholog. 2011;25:32-46. https://doi.org/10.1123/tsp.25.1.32

[71] Coudevylle GR, Ginis KAM, Famose JP, Gernigon C. Effects of self-handicapping strategies on anxiety before athletic performance. Sport Psycholog. 2008;22:304-35. https://doi.org/10.1123/tsp.22.3.304

[72] Vazou S, Ntoumanis N, Du JG. Predicting young athletes motivational indices as a function of perceptions of coach- 
and peer-created climate. Psychol Sport Exerc. 2006;7:215-233. https://doi.org/10.1016/j.psychsport.2005.08.007

[73] Ommundsen Y, Roberts GC, Lemyre P-N, Miller BW. Parental and coach support pressure on psychosocial outcomes of pediatric athletes in soccer. Clin J Sport Med. 2006;6:522-526. https://doi.org/10.1097/01.jsm.0000248845.39498.56

[74] Ntoumanis N, Taylor IM, Thogersen-Ntoumanis C. A longitudinal examination of coach and peer motivational climates in youth sport: Implications for moral attitudes, well-being and behavioral investment. Develop Psychol. 2012;48:213-233. https://doi.org/10.1037/a0024934

[75] Smith RE, Smoll FL, Cumming SP. Effects on motivational climate intervention for coaches on young athletes' sport performance anxiety. J Sport Exerc Psychol. 2007;29:39-59. https://doi.org/10.1123/jsep.29.1.39

[76] Jaakkola T, Ntoumanis N, Liukkonen J. Motivational climate, goal orientation, perceived sport ability and enjoyment within Finnish junior ice hockey players. Scand J Med Sci Sport. 2015;1-7. https://doi.org/10.1111/sms.12410

[77] Smith RE, Cumming SP, Smoll FL. Development and validation of the motivational Climate Scale for Youth Sports. J Appl Sport Psychol. 2008;20:116-136. https://doi.org/10.1080/10413200701790558

[78] Pelletier L, Rocchi MA, Vallerand R, Deci EL, Ryan RM. Validation of the revised sport motivation scale (SMS-II). Psychol Sport Exerc. 2013;14:329-341. https://doi.org/10.1016/j.psychsport.2012.12.002

[79] Pelletier LG, Fortier M, Vallerand R, Tuson K, Brière N, Blais M. Toward a new measure of intrinsic motivation, extrinsic motivation, and amotivation in sports: The Sport Motivation Scale (SMS). J Sport Exerc Psychol. 1995;(17): 35-53. https://doi.org/10.1123/jsep.17.1.35

[80] Hair J, Anderson R, Babin B, Black W. Multivariate data analysis. 8th ed. New Jersey: Cengage Learning EMEA; 2018.

[81] Deci EL, Ryan RM. Perceived autonomy support: The Climate questionnaires. http://www.psych.rochester.edu/SDT/ measures/autton_sport.html (accessed 15.may).

[82] Duda JL. The relationship between task and ego orientation and the perceived purpose of sport among high school athletes. J Sport Exerc Psychol. 1989;11:318-335. https://doi.org/10.1123/jsep.11.3.318

[83] Duda JL, Hall HK. The measurement of goal perspectives in physical domain. In: Duda JL, editor. Advances in measurement in sport and exercise psychology. Morgantown WV: FIT; 1998, 21-48.

[84] Newton M, Duda JL. The Perceived Motivational Climate in Sport Questionaire-2: Construct and predictive validity. J Sport Exerc Psychol. 1993;15:59. https://doi.org/10.1123/jsep.15.2.172

[85] Duda JL, Whitehead J. The measurement of goal perspectives in the physical domain. In: Duda JL, editor. Advances in measurement in sport and exercise psychology. Morgantown WV: FIT; 1998, 21-48.

[86] Sarrazin P, Guillet E, Cury F. The effect of coach's task - and ego-involving climate on the changes in perceived competence, relatedness and autonomy among girl handballers. Eur J Sport Sci. 2001;1(4):1-9. https://doi.org/10.1080/17461390100071404 